\title{
Retinal pigment epithelium tear after intravitreal aflibercept injection
}

This article was published in the following Dove Press journal:

Clinical Ophthalmology

25 June 2013

Number of times this article has been viewed

\section{Masaaki Saito \\ Mariko Kano \\ Kanako Itagaki \\ Yasuharu Oguchi \\ Tetsuju Sekiryu}

Department of Ophthalmology, Fukushima Medical University School of Medicine, Fukushima, Japan
Correspondence: Masaaki Saito

Department of Ophthalmology,

Fukushima Medical University School

of Medicine, I Hikarigaoka,

Fukushima 960-1295, Japan

$\mathrm{Tel}+8 \mid 24547$ I 303

Fax +8I 245482640

Email smasaaki@fmu.ac.jp
Abstract: To report a case complicated with a retinal pigment epithelium (RPE) tear after intravitreal aflibercept injection. A 78-year-old man had deteriorated visual acuity in his left eye. Fluorescein angiography showed occult choroidal neovascularization. Optical coherence tomography showed a serous retinal detachment and fibrovascular pigment epithelial detachment. He was diagnosed as typical age-related macular degeneration associated with pigment epithelial detachment and treatment consisting of three consecutive monthly intravitreal injections of aflibercept was planned. A month after the initial injection, his visual acuity had not improved. The red-free photograph showed an area of RPE defect inferior to the fovea. The fundus autofluorescence, fluorescein angiography, and optical coherence tomography clearly demonstrated the presence of an RPE tear. A second injection of aflibercept was performed due to a remaining serous retinal detachment. Although this is a single case and RPE tears may occur as a spontaneous complication of age-related macular degeneration patients, the risk of a tear should be discussed when considering aflibercept treatment for typical age-related macular degeneration patients with pigment epithelial detachment as there might be a risk for developing an RPE tear.

Keywords: age-related macular degeneration, aflibercept, pigment epithelial detachment, retinal pigment epithelium tear

\section{Introduction}

Retinal pigment epithelium (RPE) tears are a well-recognized complication of exudative age-related macular degeneration (AMD) especially in association with a pigment epithelial detachment (PED), either spontaneously or after treatments. ${ }^{1-5}$ Recently, the new antivascular endothelial growth factor (anti-VEGF) drug aflibercept (Eylea $^{\circledR}$; Regeneron Pharmaceuticals, Tarrytown, NY, USA; Bayer AG, Leverkusen, Germany) was reported by major clinical trials to have equal efficacy to ranibizumab. ${ }^{6}$ It became available for medical use in Japan in December 2012. Here, the authors report the first case substantially documented by angiographic images of a complication with an RPE tear after an intravitreal aflibercept injection.

\section{Case report}

A 78-year-old man had deteriorated visual acuity in his left eye. The best-corrected visual acuity was 20/25 at baseline (Figure 1). Fluorescein angiography (FA) showed a fibrovascular PED and occult choroidal neovascularization. FA also showed an occlusion of branch retinal vein and collaterals at the upper macula. Foveal ischemia or extensive leakage due to branch retinal vein occlusion was not demonstrated by 


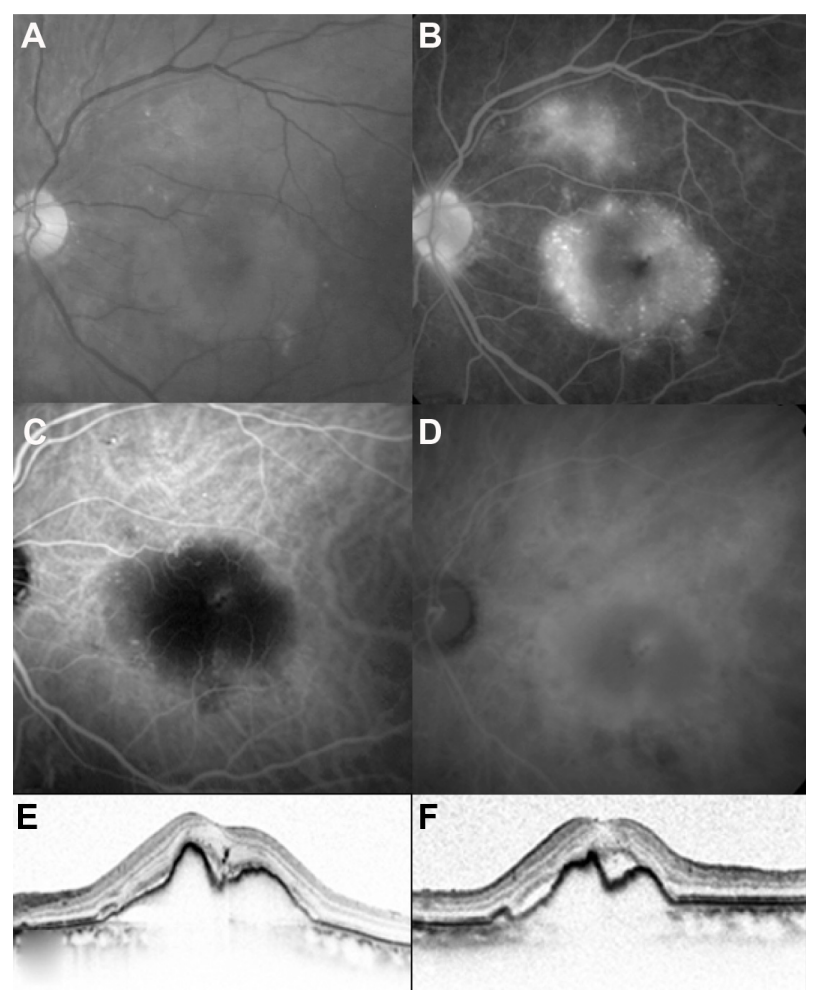

Figure I A 78-year-old man was treated with an intravitreal aflibercept injection. At baseline, the best-corrected visual acuity was 20/25. (A) Red-free photograph showing a pigment epithelial detachment, lipid, and serous retinal detachment at the macular area. (B) Fluorescein angiography image showing leakage due to occult choroidal neovascularization and a fibrovascular pigment epithelial detachment, as well as an occlusion of branch retinal vein and collaterals at the upper macula. (C and D) Early-phase (left) and late-phase (right) indocyanine green angiography showing no polypoidal lesion. (E and F) Baseline horizontal (left) and vertical (right) optical coherence tomography (Spectralis ${ }^{\circledR}$; Heidelberg Engineering, Heidelberg, Germany) images showing a serous retinal detachment and fibrovascular pigment epithelial detachment.

FA findings. Indocyanine green angiography showed no polypoidal lesion. Optical coherence tomography (Spectralis ${ }^{\circledR} ;$ Heidelberg Engineering, Heidelberg, Germany) showed a serous retinal detachment and a fibrovascular PED. He was diagnosed as typical AMD associated with PED. The treatment consisting of three consecutive monthly intravitreal injections of aflibercept was planned, and the first injection for the patient was performed. Intravitreal aflibercept $(2 \mathrm{mg} / 0.05 \mathrm{~mL}$ ) was injected $3.5-4.0 \mathrm{~mm}$ posterior to the corneal limbus into the vitreous cavity using a 30 -gauge needle after topical anesthesia was applied. A month later, the best-corrected visual acuity was 20/28 (Figure 2). The red-free photograph showed an area of RPE defect inferior to the fovea. The fundus autofluorescence showed an area of hypo autofluorescence, which corresponded to a hyperfluorescence area seen on FA and a defect of the RPE line seen on optical coherence tomography. Fundus autofluorescence, FA, and optical coherence tomography confirmed the presence of an RPE tear. A second injection

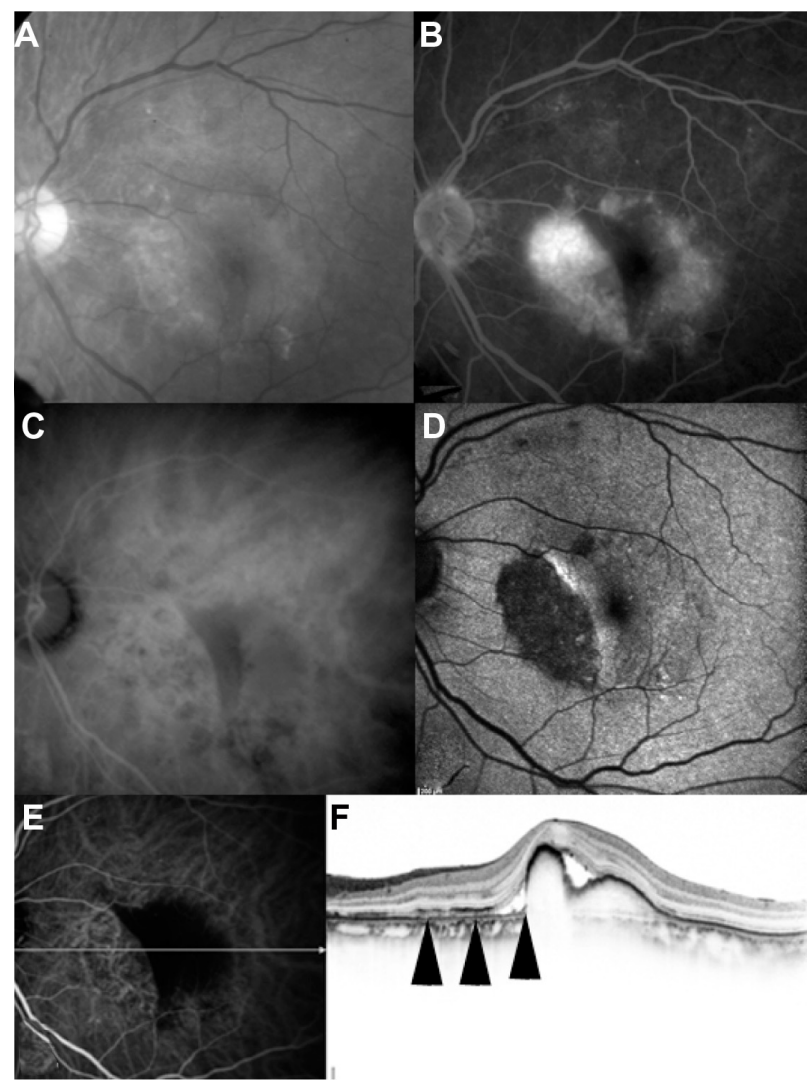

Figure $2 \mathrm{~A}$ month after the first intravitreal aflibercept injection. The best-corrected visual acuity was 20/28. (A) Red-free photograph showing an area of retinal pigment epithelium defect inferior to the fovea. (B) Fluorescein angiography image showing an area of hypofluorescence. (C) Late-phase indocyanine green angiography showing hypofluorescence. (D) Fundus autofluorescence showing an area of hypo autofluorescence. (E) Early-phase indocyanine green angiography and horizontal optical coherence tomography image. (F) Scanned by the white arrow on the left indocyanine green angiography image, which was simultaneously obtained by spectral-domain optical coherence tomography, showing defect of the retinal pigment epithelium line (arrows).

of aflibercept was performed due to a remaining serous retinal detachment.

\section{Discussion}

RPE tears may occur as a spontaneous complication in AMD patients. ${ }^{1}$ It is well known that RPE tears have also been described after various treatments such as laser photocoagulation, photodynamic therapy with verteporfin, and intravitreal injections of pegaptanib, ranibizumab, and bevacizumab. The incidence of RPE tears is reported to be $1.8 \%-27 \%{ }^{4}$ The exact pathogenesis of RPE tears remains unknown. It has been speculated that the mechanism of RPE tears is the inhibition of VEGF causing a decline in intercellular adherence ${ }^{7}$ or the increased pressure of the serous fluid exerting cohesive forces on the RPE. ${ }^{8}$ Recently, Cunningham et al retrospectively reviewed three Phase III clinical trials that reported the incidence of RPE tears after 
intravitreal ranibizumab to be $1.8 \%$ with $0.5 \mathrm{mg}$ ranibizumab, $3.0 \%$ with $0.3 \mathrm{mg}$ ranibizumab, and $1.6 \%$ in the control group. ${ }^{5}$ They also reported that 19/28 (67.9\%) RPE tears were first identified at 3 months in the treatment groups compared to $3 / 7(42.9 \%)$ in the control group. In the current case, the RPE tear was revealed at 1 month, which may be earlier than previous studies. Aflibercept binds not only all isomers of the VEGF-A family but also VEGF-B and placental growth factor. The receptor sequences of the aflibercept are more powerful (140 times) than that of ranibizumab. This binding affinity of aflibercept may be one of the causes of the earlier RPE tear.

\section{Conclusion}

To the authors' knowledge, this is the first case substantially documented by angiographic images of a complication with an RPE tear after an intravitreal aflibercept injection. While the occurrence of RPE tears may be low following any antiVEGF agent, caution should be taken when considering aflibercept treatment for typical AMD patients with PED as there may be a risk for developing an earlier RPE tear. Because this was a case report, further large and long-term prospective randomized studies are needed to determine the efficacy and safety profiles of aflibercept for AMD patients with PED.

\section{Disclosure}

The authors report no conflicts of interest in this work.

\section{References}

1. Hoskin A, Bird AC, Sehmi K. Tears of detached retinal pigment epithelium. Br J Ophthalmol. 1981;65(6):417-422.

2. Yeo JH, Marcus S, Murphy RP. Retinal pigment epithelial tears. Patterns and prognosis. Ophthalmology. 1988;95(1):8-13.

3. Pece A, Introini U, Bottoni F, Brancato R. Acute retinal pigment epithelial tear after photodynamic therapy. Retina. 2001;21(6):661-665.

4. Smith BT, Kraus CL, Apte RS. Retinal pigment epithelial tears in ranibizumab-treated eyes. Retina. 2009;29(3):335-339.

5. Cunningham ET Jr, Feiner L, Chung C, Tuomi L, Ehrlich JS. Incidence of retinal pigment epithelial tears after intravitreal ranibizumab injection for neovascular age-related macular degeneration. Ophthalmology. 2011;118(12):2447-2452.

6. Heier JS, Brown DM, Chong V, et al; VIEW 1 and VIEW 2 Study Groups. Intravitreal aflibercept (VEGF trap-eye) in wet age-related macular degeneration. Ophthalmology. 2012;119(12):2537-2548.

7. Singh RP, Sears JE. Retinal pigment epithelial tear after pegaptanib injection for exudative age-related macular degeneration. $\mathrm{Am} \mathrm{J}$ Ophthalmol. 2006;142(1):160-162.

8. Gass JD. Pathogenesis of tears of the retinal pigment epithelium. $\mathrm{Br} J$ Ophthalmol. 1984;68(8):513-519.
Clinical Ophthalmology

\section{Publish your work in this journal}

Clinical Ophthalmology is an international, peer-reviewed journal covering all subspecialties within ophthalmology. Key topics include: Optometry; Visual science; Pharmacology and drug therapy in eye diseases; Basic Sciences; Primary and Secondary eye care; Patient Safety and Quality of Care Improvements. This journal is indexed on

Submit your manuscript here: http://www.dovepress.com/clinical-ophthalmology-journal

\section{Dovepress}

PubMed Central and CAS, and is the official journal of The Society of Clinical Ophthalmology (SCO). The manuscript management system is completely online and includes a very quick and fair peer-review system, which is all easy to use. Visit http://www.dovepress.com/ testimonials.php to read real quotes from published authors. 